\title{
Immobilization of Metalloporphyrin on Functionalized SBA-15 Nanoporous Silica
}

\author{
Nurafiqah Saadon ${ }^{\mathrm{a}}$, Salasiah Endud ${ }^{\mathrm{a}, \mathrm{b}} *$, Mohd Bakri Bakar ${ }^{\mathrm{b}}$, Mahsa Khoshkhooy Yazdi $^{\mathrm{b}}$ \\ ${ }^{a}$ Novel Materials Research Group Nanotechnology Research Alliance, Universiti Teknologi Malaysia, 81310 UTM Johor Bahru, Johor, Malaysia . \\ ${ }^{b}$ Department of Chemistry, Faculty of Science, Universiti Teknologi Malaysia, 81310 UTM Johor Bahru, Johor, Malaysia. \\ *Corresponding Author: salasiah@kimia.fs.utm.my
}

\section{Article history :}

Received 01 December2015

Accepted 28 December 2015

\section{GRAPHICAL ABSTRACT}

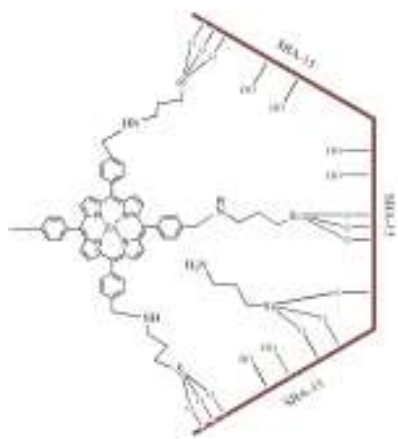

ABSTRACT

SBA-15 nanoporous silica was prepared by cooperation assembly of tetraethylorthosilicate precursor in the presence of poly (ethylene glycol)-block- poly (propylene glycol)-block- poly (ethylene glycol) copolymer surfactant and functionalized with (3-aminopropyl) triethoxysilane (APTES) via sol-gel reaction to obtain APTES-SBA-15. Tetra-(p-chlorophenyl) porphyrin (TCIPP) was synthesized using modified Alder- Longo method. Zinc was inserted into the TClPP using zinc acetate as a metal source The existance of zinc in porphyrin was confirmed by the appearance of Soret band and Q band in UVvis spectra. ZnTCIPP was also characterized using FTIR and NMR spectroscopy SBA-15 was modified with APTES to immobilize the metalloporphyrin on SBA-15 surface. The product (NH-SBA-15 ZnP) can be used as a heterogenous catalyst in various reactions. The formation of this material was confirmed by FTIR spectroscopy, XRD and BET adsorption.

Keywords: nanoporous silica, metalloporphyrins, APTES

(C) 2015 Penerbit UTM Press. All rights reserved http://dx.doi.org/10.11113/mjfas.v11n4.393

\section{INTRODUCTION}

Porphyrins are any group of compounds containing porphine structure to which a variety of side chains are attached. They are found in nature as active sites of numerous proteins. Many biological porphyrins are used as a base compound for synthetic porphyrins.

Metalloporphyrins are porphyrins that contain a metal in the centre of their ring. Metalloporphyrin species have been found in nature such as in chlorophyll and heme. Metal complexes of tetrapyrollic macrocyles play an essential role in life on earth due to their implications in many enzymatic systems [1]. Hence, synthetic analogues featuring the characteristic of porphyrin macromolecules have been expected to have a great potential for many applications. Synthetic porphyrins and metalloporphyrins have been reported to have a broad application in biological catalysts and electron transfer systems. Moreover, relative easy synthesis of porphyrins at moderate costs and have the possibilities of creating variety of structural modifications offer almost unlimited prospect to the molecular design [2].

Beside iron various types of metals such Co, Zn, $\mathrm{Cu}, \mathrm{Mn}, \mathrm{Ru}$ and many more can be inserted into the porphyrin cavity using various metal salts. There have been many researches on applications of metalloporphyrins in fields such as mimicking enzyme, ion receptor [3], pesticide photodegradation [4] and many more. The well known metalloporhyrin for mimicking of oxygenation function of enzyme, cytochrome P450 have faced a major problem which is self-destruction and dimerization of unhindered metalloporphyrin. Cytochrome P450 mimicking solved the major problem of catalyst inactivation by introducing an electronegative substitution (electron withdrawing group at meso-phenyl or $\beta$-pyrrole position) which prevents undesired decrease of catalytic activity [5].

However, metalloporphyrins which are used as homogeneous catalyst systems have several disadvantages such as their oxidative self-destruction in oxidizing media, decomposition of catalyst during reactions and recovery at the end of reaction for re-usage [6]. Homogenous catalysts are difficult to be recovered from the product, thus increase the cost of production.

One of the suggested ways to overcome these problems is to immobilize the porphyrin on a solid matrix such as alumina, silica and clays. There are advantages to this method such as increasing catalytic activity, stability and reusability. In addition, heterogenization of metalloporphyrins will prevent the formation of inactive dimers [7].

In this study, mesoporous silica sieve is chosen to be used as a support material due to its large pore size and a very high molecular mass which permit an efficient diffusion of products and reagents. These type of materials are structurally stable, environmentally acceptable and 
chemically more resistance to organic solvents than organic supports. Mesoporous materials have a highly controllable pore size, mono disperse nature of large accessible pores, high surface area and periodic nano- scale pore spacing that make them suitable for applications such as heterogeneous catalysts [8]. Deposition on silica support has positively influenced the stability of metalloporphyrin species.

Among these ordered mesoporous silica materials, SBA-15 shows higher thermal and hydrothermal stability, significantly larger unit cell size, wider and ordered pores, higher structural regularity, well defined morphologies as well as ticker pore size compared to MCM-41and MCM48. It is synthesized by triblock copolymer surfactant as a template under acidic conditions. Larger pores enable of larger molecules, which cannot be applied for materials with small pore sizes. These characteristics make them suitable for practical applications in material science and catalysis.

\section{EXPERIMENTS}

\subsection{Synthesis of APTES-SBA-15}

SBA-15 was synthesized using Zhao method [9]. Similar to other methods, $4.0 \mathrm{~g}$ of poly (ethylene glycol)block- poly (propylene glycol)-block- poly (ethylene glycol) copolymer was dissolved in $30 \mathrm{~g}$ of water and $120 \mathrm{~g}$ of $2 \mathrm{M}$ hydrochloric acid $(\mathrm{HCl})$ solution while stirring at 35 ${ }^{\circ} \mathrm{C}$. After copolymer was completely dissolved, $8.5 \mathrm{~g}$ of tetraethyl orthosilicate (TEOS) was added into the mixture and kept stirring for 20 hours. The mixture then was aged in the oven at $80^{\circ} \mathrm{C}$ overnight without stirring. The product was recovered, washed and dried. The calcinations process was performed at $1^{\circ} \mathrm{C} / \min$ up to $550^{\circ} \mathrm{C}$ for 6 hours. The pure silica SBA-15 then functionalized with (3aminopropyl) triethoxysilane (APTES) with the ratio of $0.01 \mathrm{~mol}$ of liquid silane derivatives for $1 \mathrm{~g}$ of support [10]. Calcined SBA-15, APTES and $100 \mathrm{~mL}$ of toluene were refluxed at $85^{\circ} \mathrm{C}$ for 24 hours. The resulting mixture was allowed to cool and washed repetitively using toluene and diethylether. The NH-SBA-15 was dried at ambient temperature in a desiccator.

\subsection{Synthesis of Zinc Tetra-(p-chlorophenyl) porphyrin (ZnTClPP)}

Tetrakis ( $\mathrm{p}$ - chlorophenyl) porphyrin was synthesized by modified Alder-Longo method [6]. The synthesizing process was started with refluxing $100 \mathrm{~mL}$ of propanoic acid, freshly prepared pyrrole $(0.05 \mathrm{~mol})$ and 4 chlorobenzaldehyde $(0.05 \mathrm{~mol})$ for 30 minutes. The colorless solution turned into dark purple when the mixture was boiled. Then it was filtered and washed with cold methonal and hot water to give violet solid of tetrakis ( $p$ chlorophenyl) porphyrin. Zinc- tetra-(p-chlorophenyl) porphyrin (Zn-TCIPP) was prepared by refluxing TCP (1 $\mathrm{mmol})$ and Zinc Acetate $(1 \mathrm{mmol})$ in dichloromethane (DCM) at $100{ }^{\circ} \mathrm{C}$ in an oil bath for 1 hour. Finally, the solution was filtered while it was still hot, washed with water and dried at room temperature.

\subsection{Immobilization of ZnTClPP on APTES functionalized SBA-15}

Preparation of NH-SBA-15-ZnP was carried out using method from the reported paper [6]. The Zn-tetra- (pchlorophenyl) porphyrin was added to a suspension of $\mathrm{NH}-$ SBA-15 in dry toluene and triethylamine. The mixture was refluxed at $110^{\circ} \mathrm{C}$ in an oil bath for 24 hours. The solid product then was filtered and washed with toluene, DCM and distilled water. The NH-SBA-15-ZnP was dried in the oven and grounded into fine powder.

\section{$2.4 \quad$ Characterizations}

The materials were characterized using spectroscopic and physical methods including FTIR spectroscopy (Perkin Elmer Series 1600 Spectrophotometer), UV-Vis spectroscopy (Perkin Elmer Lambda 900 UV-VIS-NIR spectrometer), ${ }^{1} \mathrm{H} \quad$ NMR Spectroscopy (Bruker DPX-400 MHz NMR spectrophotometer), Matrix Assisted Laser Desorption/ Ionization time-of-flight Mass Spectrometry (MALDI-TOF MS)(AB Sciex TOF TOF 580), XRD analysis (X-Ray Diffractiometer model Bruker D8) and Diffuse Reflectance UV-Vis spectroscopy (Perkin Elmer Lambda 15).

\section{RESULTS AND DISCUSSION}

\subsection{Characterization of TClPP and ZnTClPP}

The ${ }^{1} \mathrm{H}$ NMR spectrum of free base porphyrin gives three characteristic proton resonances: a) $\beta$ - pyrrole protons, b) imino protons, and c) meso-aryl protons [1]. From the ${ }^{1} \mathrm{H}$ NMR spectrum of TCIPP in deuterium chloroform $\left(\mathrm{CDCl}_{3}\right)$, the singlet highly shielded peak at $2.84 \mathrm{ppm}$ indicated the inner $\mathrm{N}-\mathrm{H}$ of the porphyrin. This is due to the rapidly exchanging $\mathrm{N}-\mathrm{H}$ proton at the centre of porphyrin ligand in the core of the molecule. However, this peak disappeared in $\mathrm{Zn}$ porphyrin because $\mathrm{H}$ atoms are replaced by $\mathrm{Zn}$ ions. This indicated that zinc has successfully incorporated into the core of porhyrin. The $\beta$ protons in porphine skeleton were strongly deshielded by anisotropic effect of substituent ring current. Hence, singlet peak resonated at $8.87 \mathrm{ppm}$ was attributed to the eight proton in the basic core of porphyrin (Table 1).

Figure 1 presents the FTIR spectra of TCIPP and $\mathrm{ZnTClPP}$. The results show the presence of N-H stretching vibration of pyrrole at $3445 \mathrm{~cm}^{-1}$ as well as $\mathrm{N}-\mathrm{H}$ in planarity absorption at $965 \mathrm{~cm}^{-1}$. Zinc insertion into porphyrin ring was confirmed by the disappearance of $\mathrm{N}-\mathrm{H}$ peaks in $\mathrm{Zn}$-TClPP spectrum due to the loss of $\mathrm{H}$ atom at secondary amine $(=\mathrm{N}-\mathrm{H})$ when coordinated with zinc ions. Therefore, no N-H vibration are appeared. The vibrations at $3322 \mathrm{~cm}^{-1}$ and $2921 \mathrm{~cm}^{-1}$ wavelength represent $\mathrm{C}-\mathrm{H}\left(\mathrm{sp}^{2}\right)$ stretching of macromolecule and $\mathrm{C}-\mathrm{H}\left(\mathrm{sp}^{2}\right)$ stretching of 
phenyl group respectively. The $\mathrm{C}=\mathrm{C}$ stretching of aromatic rings of phenyl appears at $1635 \mathrm{~cm}^{-1}$ and $1394 \mathrm{~cm}^{-1}$ for TCIPP while for ZnTCIPP they are appeared at $1637 \mathrm{~cm}^{-1}$ and $1338 \mathrm{~cm}^{-1}$. The $\mathrm{C}-\mathrm{Cl}$ stretching vibration is seen at both spectra at $800 \mathrm{~cm}^{-1}$ and $797 \mathrm{~cm}^{-1}$.

Table $1{ }^{1}$ H NMR data of TClPP and Zn-TClPP

\begin{tabular}{|c|c|c|c|}
\hline Porphyrins & $\beta$-pyrrole & $\begin{array}{l}\text { Imino } \\
\text { protons }\end{array}$ & $\begin{array}{l}\text { Meso-aryl } \\
\text { protons }\end{array}$ \\
\hline TCIPP & $\begin{array}{ll}8.87 & \mathrm{ppm} \\
(\mathrm{s}, 8 \mathrm{H}) & \end{array}$ & $\begin{array}{l}-2.84 \quad \mathrm{ppm} \\
\text { (s) }\end{array}$ & $\begin{array}{lr}8.15 \quad \text { ppm } \\
\left(\mathrm{d}, 8 \mathrm{H}, \mathrm{H}_{\mathrm{o}}\right), 7.77 \\
\operatorname{ppm}\left(\mathrm{d}, 8 \mathrm{H}, \mathrm{H}_{\mathrm{m}}\right)\end{array}$ \\
\hline Zn- TCIPP & $\begin{array}{ll}8.96 & \mathrm{ppm} \\
(\mathrm{s}, 8 \mathrm{H}) & \end{array}$ & - & $\begin{array}{l}8.16 \mathrm{ppm}(\mathrm{d}, 8 \\
\left.\mathrm{H}_{\mathrm{o}}\right) \\
7.76 \quad \mathrm{ppm} \\
\left(\mathrm{d}, 8 \mathrm{H}, \mathrm{H}_{\mathrm{m}}\right)\end{array}$ \\
\hline
\end{tabular}

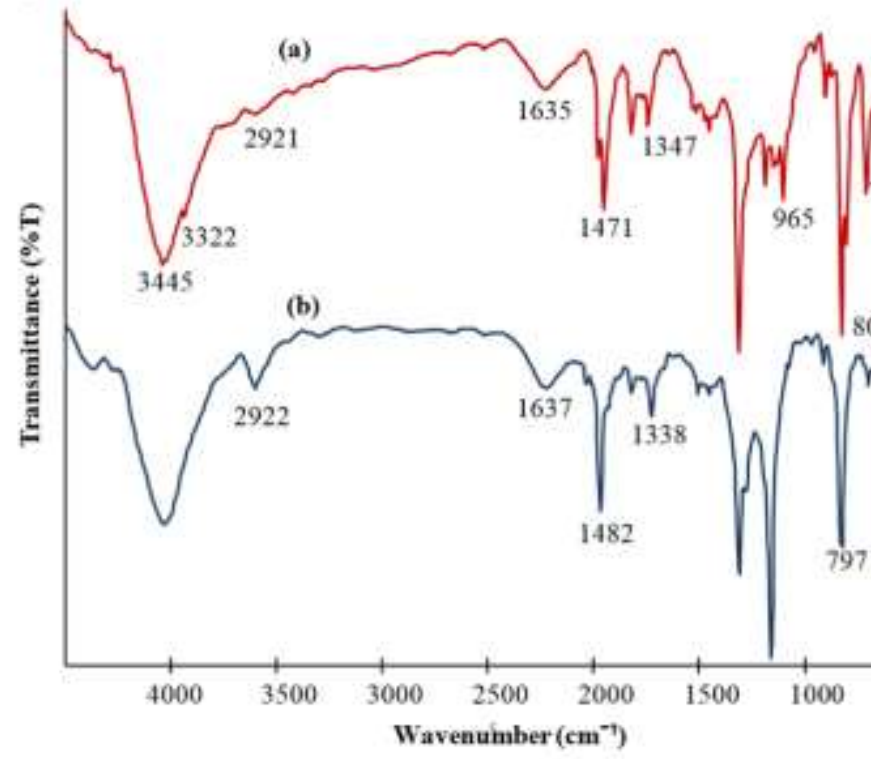

Figure.1 FTIR spectra of TCIPP and ZnTCIPP

Figure 2 shows the UV- Vis spectra of TCIPP and ZnTCIPP. The UV-Vis spectrum of TCIPP in DCM showed the etio type absorption spectrum. The maximum absorbance appears at $427 \mathrm{~nm}$ which was assigned as Soret band and four small bands at $523 \mathrm{~nm}, 557 \mathrm{~nm}, 600 \mathrm{~nm}$ and $654 \mathrm{~nm}$ were assigned as Q bands. Soret band arising from transition of $\mathrm{a}_{1 \mathrm{u}}(\pi)-\mathrm{e}_{\mathrm{g}}{ }^{*}(\pi)$ while $\mathrm{Q}$ bands are corresponding $\mathrm{a}_{2 \mathrm{u}}(\pi)-\mathrm{e}_{\mathrm{g}} *(\pi)$ transition.Both Soret and $\mathrm{Q}$ bands are 'fingerprint' of porphyrin in the absorption spectrum. After metallation process, there are only two bands, at $557 \mathrm{~nm}$ and $600 \mathrm{~nm}$. The Soret band of Zn-TCIPP was found at $430 \mathrm{~nm}$.

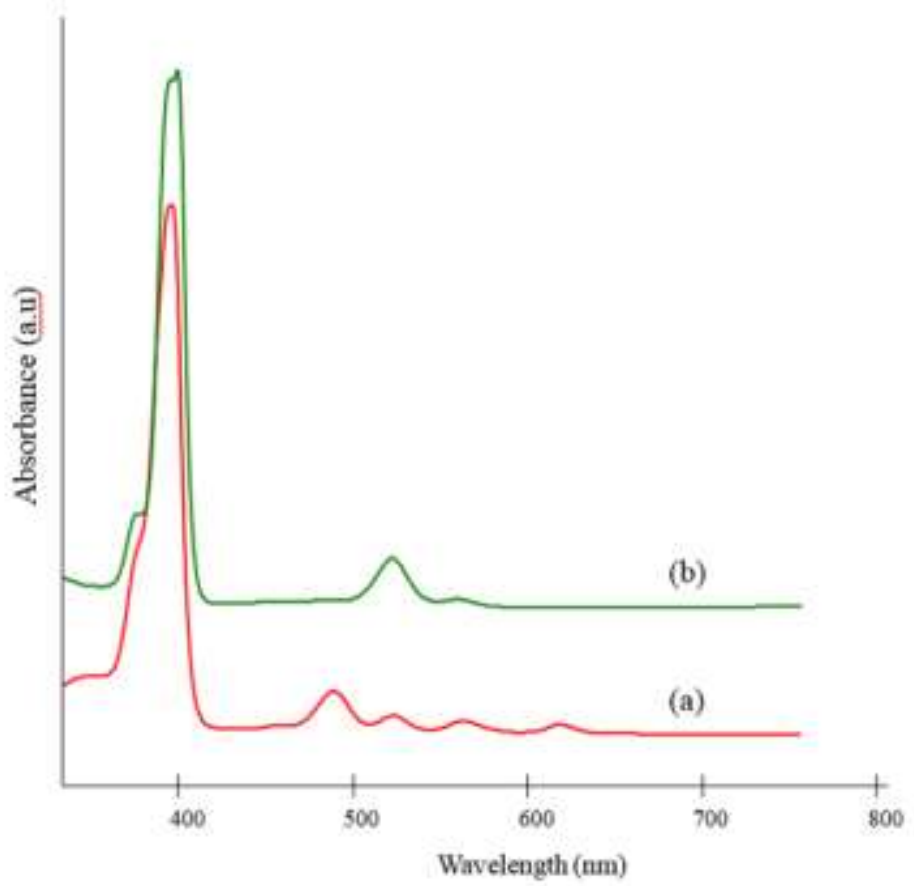

Figure.2 UV-Vis spectra of TCIPP and ZnTCIPP

Elemental analysis of TCIPP and ZnTClPP was performed using Maldi-Tof-Tof MS/MS and data is shown in Table 2.

Table 2 Comparison of molecular weight of TClPP and ZnTCIPP

\begin{tabular}{cccc}
\hline Porphyrin & $\begin{array}{c}\text { Molecular } \\
\text { structure }\end{array}$ & $\begin{array}{c}\text { Calculated } \\
\text { molecular } \\
\text { weight } \\
\text { (g/mol) }\end{array}$ & $\begin{array}{c}\text { Maldi- } \\
\text { Tof } \\
\text { analysis }\end{array}$ \\
\hline TCIPP & $\mathrm{C}_{44} \mathrm{H}_{26} \mathrm{C}_{14} \mathrm{~N}_{4}$ & 752.52 & 752.04 \\
Zn-TCIPP & $\mathrm{C}_{44} \mathrm{H}_{24} \mathrm{C}_{14} \mathrm{~N}_{4} \mathrm{Zn}$ & 815.89 & 815.94 \\
\hline
\end{tabular}

\subsection{Characterization of $\mathrm{NH}-\mathrm{SBA}-15 \mathrm{ZnP}$}

The FTIR spectra of SBA-15, NH-SBA-15 and NHSBA-15-ZnP are shown in Figure 3. The broad peak around $3400 \mathrm{~cm}^{-1}$ in all three spectra indicated that $\mathrm{Si}-\mathrm{OH}$ stretching in SBA-15 is more intense compare to NH-SBA15 and NH-SBA-15-ZnP because most of the Si atom have been reacted and form bond to $\mathrm{N}-\mathrm{H}$ group of APTES. In addition, the presence of $\mathrm{C}-\mathrm{H}$ and $\mathrm{N}-\mathrm{H}$ stretching vibration on the surface of mesoporous SBA-15 can be seen at 2938 $\mathrm{cm}^{-1}$ and $1562 \mathrm{~cm}^{-1}$ for NH-SBA-15 as well as at $2933 \mathrm{~cm}^{-1}$ and $1592 \mathrm{~cm}^{-1}$ for NH-SBA-15 ZnP. Asymmetric stretching vibration of $\mathrm{Si}-\mathrm{O}-\mathrm{Si}$ appeared at all spectra at $1086 \mathrm{~cm}^{-1}$ SBA-15, $1083 \mathrm{~cm}^{-1}$ for NH-SBA-15 and 1078 $\mathrm{cm}^{-1}$ for NH-SBA-15-ZnP. Another band at $1385 \mathrm{~cm}^{-1}$ 
appeared in both NH-SBA-15 and NH-SBA-15 ZnP spectra was representing $\mathrm{C}-\mathrm{N}$ stretching of primary amides.

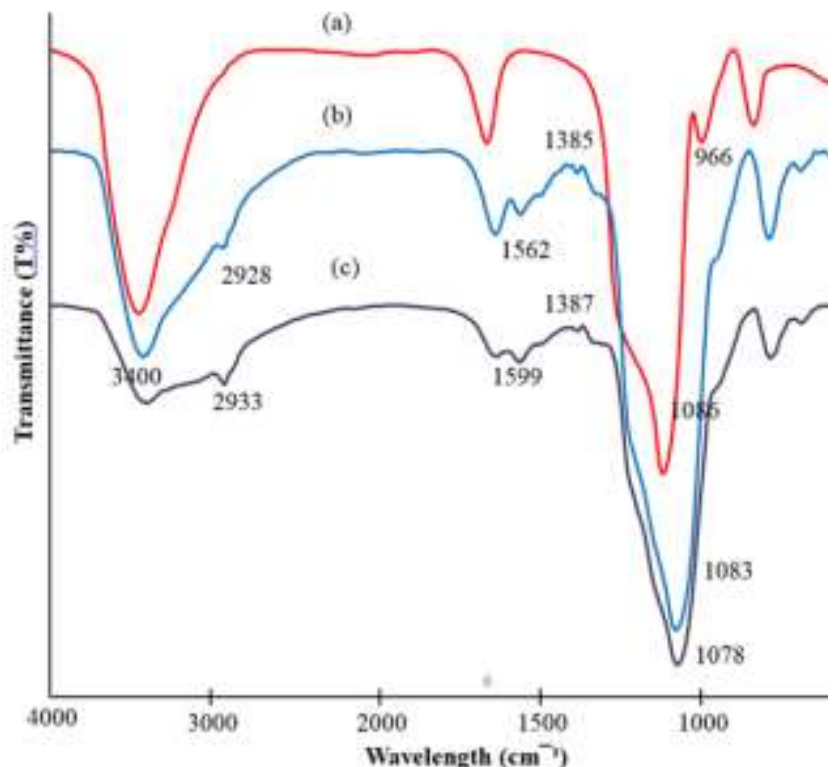

Figure.3 FTIR spectra of a) SBA-15 b) NH-SBA-15 c) NHSBA-15 ZnP

Figure 4 shows the XRD pattern of pure SBA-15 and NH-SBA-15 ZnP. The result of pure SBA-15 showed three well-resolved diffraction peaks with intense peak at $2 \theta$ of $0.9^{\circ}$ to $1.0^{\circ}$ and two small peaks at $1.2^{\circ}$ to $2.0^{\circ}$. These peaks could be indexed to ( $\left.\begin{array}{lll}1 & 0 & 0\end{array}\right),\left(\begin{array}{lll}1 & 1 & 0\end{array}\right)$ and $\left(\begin{array}{lll}2 & 0 & 0\end{array}\right)$ planes which correspond to mesostructure of hexagonal space with group symmetry of $p 6 m m$. The XRD pattern of NH-SBA15 showed a similar pattern as SBA-15 indicating that the mesoporous hexagonal structure of NH-SBA-15 $\mathrm{ZnP}$ was still retained and maintained even after functionalization with APTES and immobilization of ZnTCIPP into SBA-15. The hexagonal mesoporous structure of SBA-15 did not collapse hence, confirmed that SBA-15 has thermal stability.

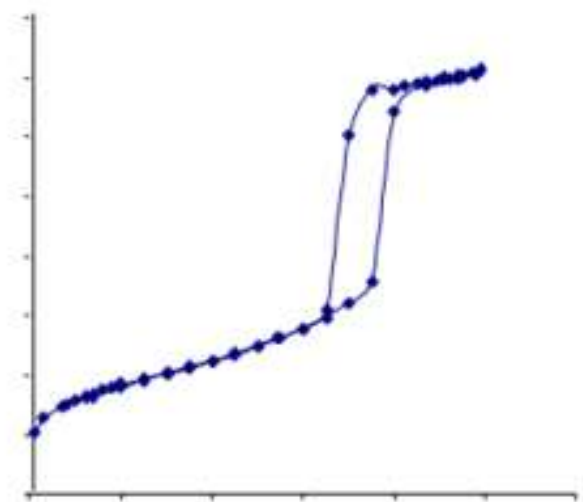

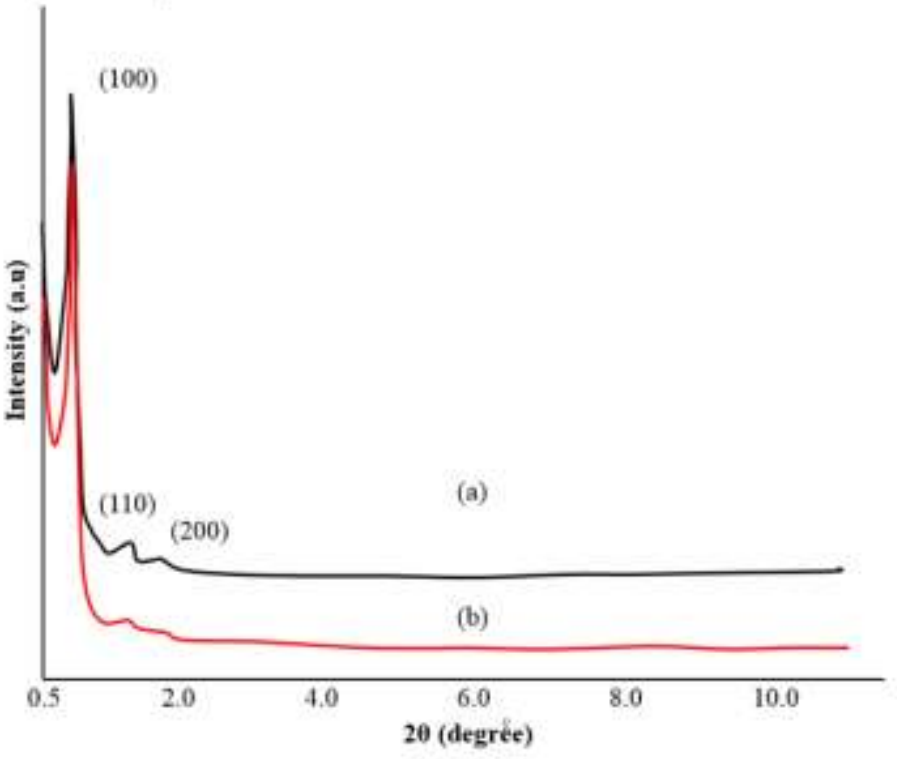

Figure.4 XRD patterns of (a) SBA-15 and (b) NH-SBA-15 Zn-P

The $\mathrm{N}_{2}$ adsorption- desorption isotherms of pure SBA-15 and NH-SBA-15 were found to be type IV curve. This is typical for mesoporous materials with well- defined capillary condensation step and uniform mesoporous materials. The characteristic feature of the type IV isotherms is hysteresis loop. Based on the IUPAC classification, isotherm of SBA-15 has the characteristic of hysteresis loop type $\mathrm{H} 1$. This $\mathrm{H} 1$ type is associated with capillary condensation in 'open-ended cylindrical channel with uniform size and shape. The surface area BET analysis of SBA-15 and NH-SBA-15 ZnP are $851 \mathrm{~m}^{2} \mathrm{~g}_{-}{ }^{1}$ and $242 \mathrm{~m}^{2} \mathrm{~g}_{-}{ }^{1}$ respectively. The decrease in the surface area of SBA-15 can be due to the immobilization of ZnClPP. The reduction in pore diameter of $\mathrm{NH}-\mathrm{SBA}-15 \mathrm{ZnP}$ compared to SBA-15 could be also due to the 'clog' by ZnTCIPP complex moiety. 


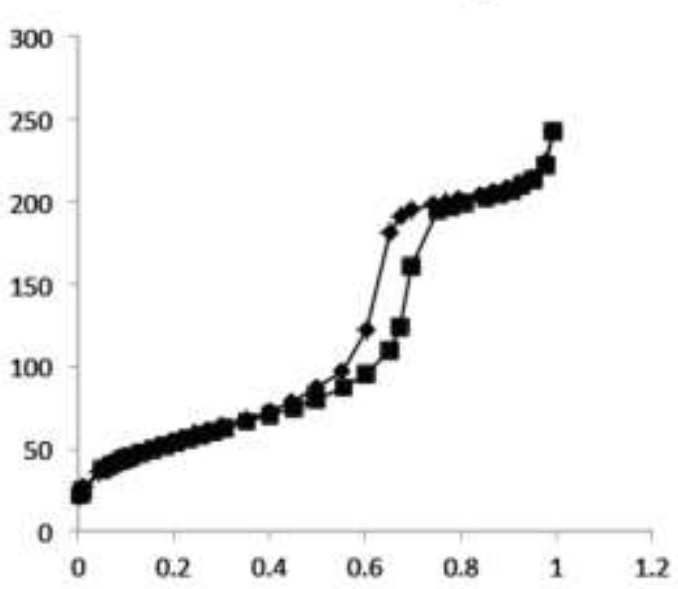

Figure. $5 \mathrm{~N}_{2}$ adsorption- desorption isotherm and pore size distribution curve of a) SBA-15 b) NH-SBA-15 ZnP

Table 2 Comparison of molecular weight of TCIPP and $\mathrm{ZnTClPP}$

\begin{tabular}{cccc}
\hline Porphyrin & $\begin{array}{c}\text { Molecular } \\
\text { structure }\end{array}$ & $\begin{array}{c}\text { Calculated } \\
\text { molecular } \\
\text { weight } \\
\text { (g/mol) }\end{array}$ & $\begin{array}{c}\text { Maldi- } \\
\text { Tof } \\
\text { analysis }\end{array}$ \\
\hline TCIPP & $\mathrm{C}_{44} \mathrm{H}_{26} \mathrm{C}_{14} \mathrm{~N}_{4}$ & 752.52 & 752.04 \\
Zn-TCIPP & $\mathrm{C}_{44} \mathrm{H}_{24} \mathrm{C}_{14} \mathrm{~N}_{4} \mathrm{Zn}$ & 815.89 & 815.94 \\
\hline
\end{tabular}

The DR-UV-Vis spectra of pure SBA-15 and NH-SBA$15 \mathrm{ZnP}$ are shown in Figure 6. Compared to pure SBA-15 spectrum, the typical intense Soret band of porphyrin appeared at $428 \mathrm{~nm}$ in the NH-SBA-15 $\mathrm{ZnP}$ spectrum. There are two more peaks called $\mathrm{Q}$ bands were detected in NH-SBA-15 ZnP spectrum at $563 \mathrm{~nm}$ and $608 \mathrm{~nm}$. The bands were red-shifted to lower energies compared to ZnTCIPP possibly due the distortion of the porphyrin ring during the immobilization of metalloporphyrin into SBA15. The DR-UV-Vis spectrum of NH-SBA-15 ZnP seems to be similar to that of $\mathrm{ZnClTPP}$ without any significant differences. This shows that the porphryin structureattached to the mesoporous silica neither was destructed nor collapsed.

\section{REFERENCES}

[1] Bajju, D.G.; Kundan, S.; Kapahi, A.; Gupta, D. J. Chem 2013 (2013). 1-14.

[2] Slota, R.; Broda, M.A.; Dyrda, G.; Ejsmont, K.; Mele, Giuseppe. Molecules (2011). 16. 9957-9971.

[3] Bao, X.; Zhang, H.; Zhang, Z.; Wu, L.; Li, Z. Inorg. Chem. Comm. 10 (2009). 728-730

[4] Silva, M.; Azenha, M.E.; Pereira, M.M.; Burrows, H.D.; Sarakha, M.; Forano, C.; Ribeiro, M.F.; Fernandes, A. Appl. Catal. B: Envi. 100 (2010). 1-9

[5] Pulkkinen, J.; Zachar, P.; Borek, V.A.; Laatikainen, R.; Kral, V. J. Mol. Catal. A: Chem. 219. (2004). 21-27

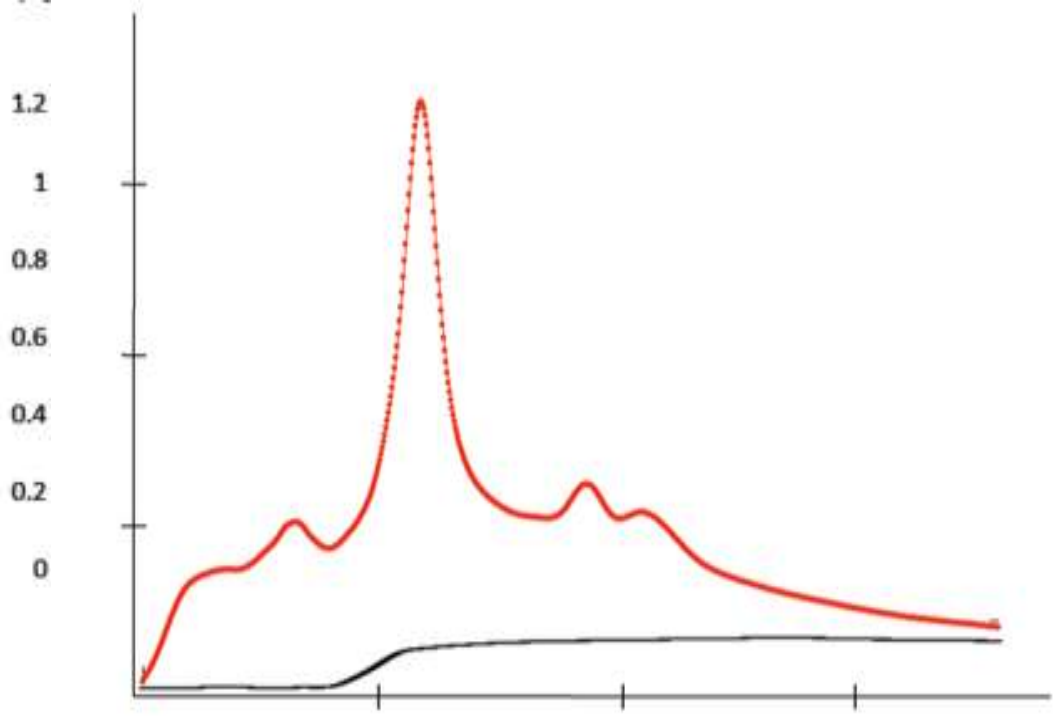

Figure.6 DR-UV-Vis spectra of (a) SBA-15 and (b) NH-SBA-15 Zn-P

\section{CONCLUSION}

The ZnTClPP was successfully synthesized by modified Alder-Longo method and zinc was inserted by using zinc acetate. The product was confirmed by the spectroscopic evidences. After the immobilization of ZnTCIPP into NH-SBA-15 the surface area of SBA-15 decreased from $851 \mathrm{~m}^{2} \mathrm{~g}_{-}{ }^{1}$ to $242 \mathrm{~m}^{2} \mathrm{~g}_{-}{ }^{1}$ but maintained its mesoporous hexagonal structure and pore shape.

\section{ACKNOWLEDGEMENT}

This research was supported by research grant R.J13000.2513.4F221, myMaster scholarship (Nurafiqah Saadon) from Ministry of Education and Universiti Teknologi Malaysia for the research facilities.

[6] Adam, F.; Ooi, W.T. Appl. Sci. A: Gen. 445-446. (2012). 252260

[7] Serwika, E.M.; Poltowicz, J.; Bahranowski, K.; Olenjniczak, Z.; Jones, W. Appl. Catal. A: Gen. 275 (2009). 9-14.

[8] Zhang, H.; Sun, Y.; Ye, K.; Zhang, P.; Wang, Y. J. Mat. Chem.15 (2005). 3181-3186

[9] Zhao, D.; Feng, J.; Huo, Q.; Melosh, N.; Fredrickson, G.H.; Chmelka, B.F.; Stucky, G.D. Sci. 279 (1998) 548-552

[10] Dragoi, B.; Dumitriu, E. Acta. Chim. Slov. 55 (2008). 277-285 